\title{
Artigo
}

\section{DIREITOS DA PESSOA SURDA: DESAFIOS À EFETIVAÇÃO DAS LEIS EDUCACIONAIS QUE REGEM A INCLUSÃO E ACESSIBILIDADE NO MUNICÍPIO DE EUCLIDES DA CUNHA}

\author{
DEAF PEOPLE'S RIGHTS: CHALLENGES TO THE EFFECTIVENESS OF \\ EDUCATIONAL LAWS GOVERNING INCLUSION AND ACCESSIBILITY IN \\ EUCLIDES DA CUNHA MUNICIPALITY
}

\section{DERECHOS DE LAS PERSONAS SORDAS: DESAFÍOS A LA EFICACIA DE LAS LEYES EDUCATIVAS QUE RIGEN LA INCLUSIÓN Y ACCESIBILIDAD EN LA CIUDAD DE EUCLIDES DA CUNHA}

\author{
Yuri Miguel Macedo \\ Ana Patrícia Aleixo de Santana Gama \\ Jamile da Cruz e Jesus \\ Nêmora Nádja Souza Dias
}

\begin{abstract}
Resumo
O presente trabalho tem como principal objetivo apresentar os diretos das pessoas surdas e elencar alguns desafios para efetivação das leis educacionais que regem a inclusão e acessibilidade no município de Euclides da Cunha - Ba. Partindo do pressuposto de que se essas leis forem efetivadas, com qualidade, os surdos terão a possibilidade de desfrutar de tudo que a sociedade oferece e assim sentir-se, verdadeiramente, incluídos e valorizados dentro das suas possibilidades, especificidades e singularidades. Outra finalidade da pesquisa é refletir sobre a realidade desse município e o quanto ainda é necessário galgar para atingirmos a real efetivação das leis que regem as pessoas com surdez. Trata-se de uma pesquisa com a proposta de dialogar sobre a situação desses indivíduos com a sociedade e abordar possíveis caminhos para o avanço dessas efetivações.
\end{abstract}

\begin{abstract}
The present work has as main goal to present the rights of deaf people and to list some challenges for the full achievement of the educational laws governing the inclusion and accessibility in Euclides da Cunha city, state of Bahia. Starting from the assumption that if these laws are effective with quality to the deaf, they will be able to enjoy all that society offers and thus create the necessary conditions to enjoy everything and thus feel truly included and valued within their possibilities, specificities and singularities. Another purpose of the research is to reflect on the reality of this city and how much is still needed to reach the real achievement of the laws governing deafness. It is a research with the proposal to dialogue about the situation of these individuals with society and to address possible ways to search, plant and harvest.
\end{abstract}

\section{Resumen}

El presente trabajo tiene como objetivo principal presentar los derechos de las personas sordas y enumerar algunos desafíos para la efectividad de las leyes educativas que rigen la inclusión y la accesibilidad en el municipio de Euclides da Cunha - Ba. Basado en el supuesto de que si se implementan estas leyes, con calidad, los sordos tendrán la posibilidad de disfrutar de todo lo que la sociedad ofrece y así 
sentirse verdaderamente incluidos y valorados dentro de sus posibilidades, especificidades y singularidades. Otro propósito de la investigación es reflexionar sobre la realidad de este municipio y cuánto más se necesita hacer para lograr la implementación real de las leyes que rigen a las personas con sordera. Es una investigación con la propuesta de dialogar sobre la situación de estos individuos con la sociedad y abordar las posibles formas de avanzar en estos logros.

Palavras-chave: Surdez; Educação; Acessibilidade; Legislação; Inclusão.

Keywords: Deafness, Education, Accessibility, Laws and Inclusion.

Palabras claves: Sordera; Educación; Accesibilidad; Legislación; Inclusión.

\section{INTRODUÇÃO}

Refletindo sobre a Educação Especial, no Brasil, é perceptível que ocorreram evoluções. A legislação oferece, sem dúvida, vantagens educacionais no que tange à inclusão. Porém, em outra vertente, emana discussões acerca das ações que poderiam ser colocadas em prática e que, na maioria das vezes, falham, dificultando que essa Educação alcance os alunos como está previsto nos documentos que asseguram o ingresso desses discentes nas instituições escolares. Tem-se conhecimento que vários direitos foram garantidos na Constituição Federal de 1988, no documento da Política Nacional da Educação Especial na Perspectiva da Educação Inclusiva, no Conselho Nacional da Educação, na LDB, nos decretos voltados para a inclusão. Conforme a Constituição de 1988, um dos objetivos, no cap. IV:

é garantir o acesso, a participação e a aprendizagem dos alunos com deficiência, transtornos globais do desenvolvimento e altas habilidades/superdotação nas escolas regulares, orientando os sistemas de ensino para promover respostas às necessidades educacionais especiais (LDB, 1988. p. 01).

Mediante a citação, é notório que existem diversas leis que garantem e asseguram a inserção. Contudo, percebe-se que na prática há uma dissonância entre lei e realidade. Diante dessa situação, fez-se necessário investigar a aplicabilidade das leis e como os alunos com necessidades especiais estão sendo inseridos na educação do município de Euclides da Cunha, bem como corroborar se está havendo investimentos tanto nas instituições quanto na formação dos docentes, a fim de buscar políticas públicas que efetivem e certifiquem a inclusão e acessibilidade dos discentes.

O desenvolvimento dessa pesquisa será realizado por meio de entrevistas com docentes da rede e do levantamento de dados recolhidos na Secretaria Municipal da Educação. A análise dos dados possibilitará a ponderação sobre os investimentos, as formações docentes e, principalmente, se estão cumprindo com um dos princípios básicos previsto por lei: o direito de todos os indivíduos de frequentar uma escola que os eduquem e leve-os a obter autonomia na aprendizagem.

Aproveitando o ensejo, será refletido também acerca de como está acontecendo a Educação de surdos, visto que de acordo com a lei $n^{\circ} 10.436$, de 24 de abril, de 2002, a Língua Brasileira de Sinais-LIBRAS dispõe de diversos capítulos e decretos que garantem o reconhecimento da Libras como meio legal de comunicação e expressão da pessoa surda. Mas vale destacar 
que, apesar dessa garantia, não há efetivação da mesma. Por isso, é relevante a luta pela Educação Especial, pois como afirma MAZZOTA (1996) em sua obra "Educação especial no Brasil: história e políticas públicas", deve-se repensar a organização educacional dos níveis macro até o micro, contemplando desde a gestão escolar até a comunidade na qual esses discentes estão inseridos para que se sintam realmente incluídos e valorizados dentro das suas possibilidades. Mas, para isso, precisa-se da ação de todos enquanto sociedade bem como é necessário conhecer os direitos e deveres a fim de lutar por políticas públicas.

\section{EDUCAÇÃO ENQUANTO DIREITO ADQUIRIDO}

Tanto a Constituição brasileira de 1988, quanto a LDB no 9394/1996Leis de Diretrizes e Bases da Educação, garantem que a educação é um direito de todos, papel do estado e da família, no entanto nem sempre esse direito é garantido à todos os cidadãos brasileiros, sobretudo aos que requer algum atendimento especial especializado.

De acordo com Macedo, Oliveira e Peçanha (2019), elucida que,

no espaço escolar essa lei deve estar comboiada de políticas que gerem a discussão sobre os temas raciais, na escola, no bairro, no município, no país e no mundo. Devemos atentar para o fato de a lei vir para tentar estancar a sangria do racismo e esse não está presente apenas no espaço escolar, mas é vinculado em toda a sociedade.

Embora a palavra direito remeta a ideia de conceder, introduzir, fazer parte, na prática esse termo terá um longo caminho a galgar. Para compreender tal afirmativa, basta realizar uma análise desde a educação na antiguidade aos dias atuais e perceberá que houve avanços, mesmo que a passos lentos no que remete ao direito a educação, no entanto há muito a ser realizado e cumprido.

$\mathrm{Na}$ Constituição Federal em seu art. 58, pode-se encontrar os direitos assegurados ao aluno com necessidade especial e nesse parágrafo encontrase a seguinte definição sobre da educação especial: "educação especial e a modalidade de ensino escolar ofertada preferencialmente na rede regular de ensino, para educandos com deficiência, transtornos globais do desenvolvimento e altas habilidades ou superdotação". No entanto, na prática não é bem assim que ocorre e seja qual for a necessidade especial do discente em sua maioria ficará a mercê do poder público, o qual não está apto a lidar com todas as situações.

Os sistemas de ensino assegurarão aos educandos com deficiência, transtornos globais do desenvolvimento e altas habilidades ou superdotação:

I - currículos, métodos, técnicas, recursos educativos e organização específica para atender às suas necessidades

II terminalidades específica para aqueles que não puderem atingir o nível exigido para conclusão do ensino fundamental, 
em virtude de suas deficiências e aceleração para concluir em menor tempo o programa escolar para os superdotados.

III - professores com especialização adequadas em nível médio ou superior, para atendimentos especializados, bem como professores do ensino regular capacitados para a integração desses educandos nas classes regular de ensino.

IV - educação especial para o trabalho, visando a sua efetiva integração na vida em sociedade, inclusive condições adequadas para os que não revelarem capacidade de inserção no trabalho competitivo, mediante articulação com os órgãos oficiais afins, bem como para aqueles que apresentam uma habilidade superior nas áreas artística, intelectual ou psicomotora.

V - acesso igualitária aos benefícios dos programas sociais suplementares disponíveis para o respectivo nível do ensino regular.(BRASIL,2013).

Embora nos termos da lei o aluno com necessidades especiais tenha seu direito, na prática essa lei nem sempre é totalmente cumprida, pois o que se ver são cadeiras ocupadas por alunos em sua maioria figurantes para cumprirem normas que determinam sua matricula na escola. Desses alunos "inclusos" determinados por essas leis, poucos terminam com êxito os estudos, alguns desistem no percurso mediante a tantas barreiras enfrentadas no ambiente escolar.

Diante do exposto, o presente artigo norteará seu foco principal à pessoa surda, a qual assim como os demais possuidores de atendimentos especiais, também enfrentam sérias barreiras em seu caminho desde no ambiente familiar, na sociedade, na escola e no trabalho, dessa forma criou-se então a Língua Brasileira de Sinais, em 24 de abril de 2002, foi criada a Lei no 10.436, a qual coloca a LIBRAS no grupo das línguas no Brasil, sendo essa língua o meio de comunicação das comunidades surdas.

Art. $1^{\circ}$ É reconhecida como meio legal de comunicação e expressão a Língua Brasileira de Sinais - Libras e outros recursos de expressão a ela associados. Entende-se como Língua Brasileira de Sinais - Libras a forma da comunicação e expressão, em que o sistema linguístico da natureza visualmotora, com estrutura gramatical própria, constituem um sistema linguístico de transmissão de ideias e fatos, oriundos de comunidades de pessoas surdas do Brasil. (Brasil,2002).

Sendo a Libras institucionalizada enquanto lei, passa essa então a ser no referente a inclusão enquanto disciplina obrigatória nos cursos de formação para o magistério e nas licenciaturas, no entanto ter o contato em apenas uma disciplina não é o suficiente a deixar o professor proficiente em LIBRAS. Em alguns estados e municípios a Libras já é disciplina obrigatória no currículo escolar, recentemente no ano de 2019 o atual presidente da república do Brasil, anunciou a possibilidade da obrigatoriedade dessa disciplina em todo território nacional, no entanto para estudiosos não basta incluir a disciplina enquanto obrigatória e ofertar ao aluno surdo matricula na escola regular, mas 
sim a ampliação de escolas bilíngues para assim obter uma língua em excelência.

De acordo com o site. Edição do Brasil (2017), tendo como base dados do o Instituto Brasileiro de Geografia Estatística - IBGE, de acordo com o último senso de 2010, há no Brasil cerca de 9,7 milhões de pessoas com deficiência auditiva, seja ela parcial ou total, desse contingente poucos tem acesso à educação de qualidade sobretudo a LIBRAS, nesse contexto há uma contradição mediante a Lei da educação inclusiva, bem como do direito a educação $\mathrm{n}^{0} 13.146$, de 6 de junho de 2015 em seu artigos 22 e 27 os quais garantem direito a educação à pessoa surdas ou com deficiência auditiva, asseguradas educação inclusiva em todos os níveis de ensino e aprendizado durante toda sua vida.

Sabe-se que parte dessa população parcialmente surda ou com surdez total enfrenta constantemente barreiras em seu dia-a-dia, desde a obter 0 acesso a educação, a manter-se informado, o acesso a informação é outra contradição da já citada lei 13.146, que em seu Art. 63 do acesso a informação e a comunicação diz:

É obrigatória a acessibilidade nos sítios da internet mantidos por empresas com sede ou representação comercial no país ou órgãos de governo para usos da pessoa com deficiência, garantindo-lhe o acesso às informações disponíveis conforme as melhores práticas e diretrizes de acessibilidade adotadas internacionalmente.

Diante das afirmativas apresentadas, a pessoa surda sente-se um estrangeiro dentro de seu próprio país, já que essa em sua maioria não consegue se comunicar sobretudo nos ambientes sociais com a Libras, tão pouco ter o acesso a interpretes ou tradutores dessa língua - Libras - tanto dentro quanto fora de casa.

\section{DIREITO ENQUANTO CIDADANIA}

O Direito enquanto cidadania à pessoa surda assim como ter acesso a educação também ter seus diretos de cidadãos cumpridos é de extrema relevância. Ofertar escolas preparadas ao ensino da Libras não é um mero desejo a ser alcançado é um dever e merece ser devidamente cumprido de acordo com os rigores da lei, quem não ofertasse ao que diz a lei pagaria seu ônus. A possibilidade de um professor interprete de libras, ou tradutor e capacitação a todo corpo docente da escola, quiçá a todos os membros que compõem a equipe escolar deveria ser uma realidade possível e acessível à toda população brasileira, entretanto por falta desses profissionais nas instituições de ensino o aluno surdo sente-se isolado, e por não compreender e tão pouco ser compreendido em sua maioria acaba por desistir da escola e em alguns casos até tenta dá continuidade aos estudos, mas como quase sempre é ignorado acaba perdendo o estímulo e prazer pelos estudos.

É um princípio dos direitos humanos que toda criança seja educada em sua própria língua (Hornenberger, 1998): não se trata de uma concessão da escola, trata-se do único meio 
possível de o surdo desenvolver seus mecanismos cognitivos e sociais (Gesser, 2017)

No entanto, nem tudo está perdido há no território nacional algumas escolas bilíngues as quais oferecem maior possibilidades do domínio da Libras, nessas Instituições o discente surdo aprende com os seus as língua materna e aliada a essa a Libras, porém cada uma em seu espaço, já que ambas são línguas distintas com regras e normas diferentes.

$\mathrm{O}$ art. 5ㅇ da constituição garante ao ensino da Libras docentes com formação na língua de sinais, para que assim esses atuem desde a educação infantil aos anos iniciais do ensino fundamental. Sua formação será garantida principalmente via cursos de pedagogia ou normal superior. Essa formação poderá ser ainda garantida por organizações da sociedade civil, comunidade surda desde que sejam certificadas por uma instituição habilitada a tal certificação.

Sendo assim, sendo a libras um direito adquirido deve ser garantido, pois á pessoa surda aprender essa língua é muito mais que adquirir uma linguagem é assumir seu lugar no mundo, possuir uma identidade não apenas letrada, mas cultural.

Como a identidade cultural de um grupo de surdos que se define enquanto grupo diferente de outros grupos. Essa cultura é muito cetada, mas apresenta características que são específicas: ela é visual, traduz-se de forma visual. As formas d organizar o pensamento e a linguagem transcendente as formas ouvintes. (Gesser, 2017)

Sendo o direito a educação um dever a ser cumprido, bem como direito enquanto cidadania e fazer valer o cumprimento dessas leis é papel de toda população brasileira, não apenas da comunidade surda, tão pouco da pessoa surda, afinal o acesso a educação deve ser igual à todos independente de qualquer condição física, psíquica, social ou qualquer tipo de condição humana.

\section{INCLUSÃO OU INSERÇÃO?}

Durante a entrevista realizada na Escola Municipal José Bezerra Neto com uma discente surda e uma docente, ambas pertencentes à cidade de Euclides da Cunha - Ba, foram detectadas inúmeras dificuldades relacionadas ao trabalho com pessoas com deficiência auditiva.

Refletindo sobre a Educação de Surdos, no Brasil, é perceptível que ocorreram evoluções. A legislação oferece, sem dúvida, vantagens educacionais no que tange à língua de sinais uma vez que fica nítido que ela foi reconhecida (deixando de ser um amontoado de mímicas para ser uma língua com estrutura própria) e está se difundindo. Porém, em outra vertente, emana discussões acerca das ações que poderiam ser colocadas em prática e que, na maioria das vezes, falham, dificultando que essa Educação alcance aos alunos surdos como está previsto nos documentos que asseguram a inclusão.

Tem-se conhecimento que vários direitos foram garantidos na Constituição Federal de 1988, no documento da Política Nacional da Educação 
Especial na Perspectiva da Educação Inclusiva, no Conselho Nacional da Educação, na LDB, nos decretos voltados para a inclusão. Conforme a Lei de Diretrizes e Bases da Educação Brasileira (LDB 9394/96) um dos objetivos

é garantir o acesso, a participação e a aprendizagem dos alunos com deficiência, transtornos globais do desenvolvimento e altas habilidades/superdotação nas escolas regulares, orientando os sistemas de ensino para promover respostas às necessidades educacionais especiais (BRASIL, 1988)

É nítido que existe a inserção dos discentes, porém é um paliativo cruel, analisando a entrevista, percebe-se que não há a inclusão e necessitamos dela para obter avanços reais e melhorias na educação desses alunos, as leis e propostas contidas nesses documentos carecem ser postas em prática, visto que um dos direitos garantidos pela Lei no 10.436/02 é que a Língua Brasileira de Sinais seja o meio legal de comunicação e expressão e deve ser inclusa como parte integrante do currículo nos cursos de formação de professores e de fonoaudiologia.

As colocações acima citadas são confirmadas quando a docente entrevistada expressa que "na lei é tudo muito bonito. Mas na prática, nada funciona. Abriram espaço para a discente, todavia, não deram suporte e, nem dão, para os docentes que regem classes com alunos com necessidades especiais, localizadas principalmente nas periferias, povoados, como é o meu caso...". É notável que a docente não tem apoio e que as leis e propostas para a educação de surdos não são efetivadas e eficientes.

Ainda ressaltaram a importância do Atendimento Educacional Especializado- AEE, ativo e com apoio real, visto que, conforme a Política Nacional da Educação Especial na Perspectiva da Educação Inclusiva (MEC/2008), dentre outras ações, deve haver: "Atendimento educacional especializado; Formação de professores para o atendimento educacional especializado e demais profissionais da educação para a inclusão escolar; Participação da família e comunidade". Por isso, tem que ser oferecido atendimento ao aluno e ao professor, formação. Dando condições autênticas à aprendizagem e ao ensino.

Em uma das falas da professora, é percebível que não há estrutura na escola, falta materiais adequados e cursos de aperfeiçoamento que possibilitem ao docente trabalhar com alunos surdos e, isso, é papel do poder público, já que está na LDB, os sistemas de ensino devem assegurar que os profissionais em educação estejam especializados ou devidamente capacitados para atuar com qualquer pessoa especial na sala de aula. É notório que os órgãos governamentais não estão investindo, de forma adequada, nas escolas e nos centros especializados tanto no que concerne à estrutura quanto no fornecimento de suporte aos educadores e aos pais, e essa realidade somente será transformada com a parceria entre governo, escola, família e comunidade.

É relevante destacar o papel da família no acompanhamento e na participação escolar, uma vez que a educação apenas evolui quando as partes envolvidas desempenham a sua função. Mas, deve ser observado também que muitos pais não sabem os direitos que os filhos possuem. Por isso, como 
reivindicar por algo que não se conhece? Vale destacar também, que a LDB propõe em se Art. 59, que a escola deve oferecer currículos, métodos, recursos para atender esses educandos. Porém, essas mudanças, já não são efetivadas nos currículos e na metodologia para a educação dos discentes surdos.

Diante das inúmeras respostas da docente entrevistada, dar-se um destaque especial quando expressa "tento inserir... Faço de tudo para que ela se sinta incluída. Além disso, realizo as atividades escritas e orais conforme as necessidades dela. Gosto, também, de explorar a dicção, e, em alguns momentos, sento com ela para acompanhá-la nas atividades." A professora argumenta como se dá a comunicação e a educação da discente e qual método ela costuma usar - o oralismo - para que assim, ela possa aperfeiçoar a dicção de sua aluna surda.

Depois da revolução industrial, as pessoas com deficiência são tidas como objetos que precisam ser consertados e com essa ideia equivocada surgem métodos de educação para surdos, o oralismo é um deles. Esse método tem como objetivo fazer o surdo a falar, para que assim pudesse ser visto como "normal". Porém, essa educação não fazia com que os surdos estivem no mesmo nível escolar de ouvintes e com o mesmo conteúdo. Durante a entrevista com a discente preza pelo o oralismo e pela aquisição da escrita e, diante disso, ficou-se constatado o quanto a sociedade, ainda, vive as consequências da insciência de seu povo, na qual é consumida a cultura da alienação e do condicionamento. Por isso, é necessário que haja a efetivação das leis e que seja disponibilizada capacitação aos professores. A concretização, do decreto solucionaria vários problemas relacionados a educação da pessoa surda, pois ela oferece o direito de equidade, inclusão social e cidadania. Além de dar uma atenção especial em relação aos profissionais de Libras, professor, intérprete para a capacitação deles, pois não adianta trabalhar/estudar com surdos quando não é disponibilizado subsídios para que isso aconteça.

Não tem como falar em direito a educação à pessoa surda sem capacitar os docentes para lidar com as diferenças e diversidades de sujeitos no espaço escolar. Precisa incluir e não inserir, contudo o papel das escolas atuais, em sua grande maioria, está sendo o contrário, os alunos estão sendo lesados e inseridos em um ambiente sem que haja qualquer adaptação ou adequação para recebê-los com qualidade, aceitando-os apenas como mais um membro que precisa se adaptar as regras pré-estabelecidas, todavia é necessário saber que a escola precisa se adaptar e não o aluno, este precisa ser incluído, a instituição é responsável por criar as condições necessárias para desfrutar de tudo e assim se sentir-se realmente incluídos e valorizados dentro das suas possibilidades, especificidades e singularidades.

\section{LEI DE ACESSIBILIDADE, DE ONDE VEM PARA ONDE VAI}

A Lei $n^{\circ} 10.098$, de 19 de dezembro de 2000, reconhecida como lei da acessibilidade, determina regras para que haja o devido acesso de pessoas com deficiência ou mobilidade reduzida em qualquer ambiente por meio do banimento de qualquer obstáculos e barreiras existente no pais, incluindo os acessos públicas, os prédios, os transportes, o transito e principalmente o meio 
de comunicação, porém essa lei é mais uma que precisa ser legitimada, efetivada e garantida a todos os indivíduos brasileiros.

Há inúmeras leis que não são reconhecidas ou cumpridas. Existe um processo de desigualdade alimentado pelo poder público sempre que não encontramos nele meios para diminuir o abismo que existe entre o acesso e as pessoas com deficiência. Vários direitos foram garantidos, contudo na prática são apenas leis que precisam ser concretizadas para que pessoas com deficiência tenham as condições necessárias para desfrutar de tudo que a sociedade pode oferecer.

Dentro no universo do surdo temos a Língua Brasileira de Sinas como o meio de comunicação das comunidades surdas brasileiras, mas para além da libras possuímos outros meios de comunicação que também não temos 0 acesso devido, notamos que para o surdo sentir-se realmente incluído e valorizado dentro das suas possibilidades, especificidades e singularidades é necessário que haja a real efetivação das leis, acesso a profissionais habilitado, capacitação de qualidade para esses professores e acessibilidade nos espaços físico.

A lei 10.098, no Art. $2^{\circ}$ estabelece definições que asseguram a possibilidade e condição para que pessoas com deficiência tenham, com segurança e autonomia, a liberdade e acesso de usufruir desses ambientes sem nenhum obstáculo que os impeçam.

I - acessibilidade: possibilidade e condição de alcance para utilização, com segurança e autonomia, de espaços, mobiliários, equipamentos urbanos, edificações, transportes, informação e comunicação(...), tanto na zona urbana como na rural, por pessoa com deficiência ou com mobilidade reduzida.

II - barreiras: qualquer entrave, obstáculo, atitude ou comportamento que limite ou impeça a participação social da pessoa, bem como o gozo, a fruição e o exercício de seus direitos à acessibilidade, à liberdade de movimento e de expressão, à comunicação, ao acesso à informação, à compreensão, à circulação com segurança, entre outros.

VIII - tecnologia assistiva ou ajuda técnica: produtos, equipamentos, dispositivos, recursos, metodologias, estratégias, práticas e serviços que objetivem promover a funcionalidade, relacionada à atividade e à participação da pessoa com deficiência ou com mobilidade reduzida, visando à sua autonomia, independência, qualidade de vida e inclusão social;

IX - comunicação: forma de interação dos cidadãos que abrange, entre outras opções, as línguas, inclusive a Língua Brasileira de Sinais (Libras), a visualização de textos, o Braille, o sistema de sinalização ou de comunicação tátil, os caracteres ampliados, os dispositivos multimídia, assim como a linguagem simples, escrita e oral, os sistemas auditivos e os meios de voz digitalizados e os modos, meios e formatos aumentativos e alternativos de comunicação, incluindo as tecnologias da informação e das comunicações. (BRASIL,2000)

A lei de acessibilidade é mais um princípio que deveria ser seguido de fato, contudo é mais um direito que entra no rol da prática falida, onde não é 
inteiramente cumprida, pois ainda encontramos muitas falhas, poucas resoluções e apoios, vindo de poderes públicos, para realmente incluir esses cidadãos.

\section{EDUCAÇÃO BÁSICA EM EUCLIDES DA CUNHA}

Para refletir sobre a aplicabilidade das leis, a garantia efetiva dos direitos e inclusão dos discentes com necessidades especiais no município de Euclides da Cunha, interior da Bahia, foi realizada uma entrevista com uma das coordenadoras da Secretaria Municipal de Educação a fim de adquirir um levantamento de dados e analisar a "real situação" na qual a cidade se encontra no que concerne à Educação Especial e Inclusiva.

Segundo as informações colhidas, a cidade possui 07 creches e 50 escolas incluindo fundamental I e II, cerca de 600 profissionais em educação, porém apenas 05 são especializados e atuam na área da educação especial e inclusiva. No que diz respeito à acessibilidade, disseram que aproximadamente $70 \%$ das instituições estão com infraestrutura adequada e 30\% ainda precisam de reformas e adequações.

Eles não disponibilizaram com exatidão quantas escolas recebem alunos com necessidades especiais, o quantitativo conforme suas respectivas deficiências. A coordenadora justificou que estão iniciando esse processo de sondagem, que a demanda na secretaria é significativa e que faltam funcionários ou alguém específico para realizar esse levantamento. Ainda explicou que a coordenadora contratada do SEEBA, solicitou essas questões. Mas, ainda estavam em construção, que é um processo lento de contagem do censo escolar.

\section{O INGRESSO DOS ALUNOS E A INCLUSÃO ESCOLAR}

Debruçando-se sobre os dados transmitidos, diversos aspectos podem ser pontuados e merecem um olhar minudente acerca da inclusão escolar. Diante do que foi apresentado, é destacável a falta de organização e controle de dados, visto que ainda não se tem domínio exato acerca, por exemplo, da quantidade de discentes com necessidades especiais e o tipo de deficiência que possuem. Esse levantamento é imprescindível para poder investir e sanar dificuldades com relação ao ato de incluir esses alunos. Essa situação induz a um questionamento: como assegurar os direitos das pessoas com necessidades especiais e criar políticas públicas no município se não tem um mapa completo da realidade da educação especial e inclusiva?

Outro fator que merece ser salientado é a falta de acessibilidade, já que segundo as informações na questão ํo 4, cerca de $70 \%$ das instituições escolares já possuem adequações estruturais. Porém, outras ainda necessitam de reformas. Tem-se conhecimento que perante a legislação, as escolas precisam estar adaptadas para receber os discentes. De acordo com a Lei de Inclusão $n^{0} 13.146 / 15$ as salas de aula se tornaram inclusivas, agregando diversas deficiências físico-motoras e cognitivas. Por essa razão, têm a incumbência de "assegurar e promover, em condições de igualdade, 0 exercício dos direitos e das liberdades fundamentais por pessoa com deficiência, visando à sua inclusão social e cidadania" (Brasil, 2015, p. 1), 
propiciando a garantia do amplo direito de desenvolvimento para todo cidadão. A atual LDBEN Lei no 9.394/96, especificamente no Art. 59, vem corroborar que é dever da escola viabilizar currículos, métodos, recursos para atender esses educandos.

Analisando os dados, um ponto primordial diz respeito ao funcionamento do AEE (Atendimento Educacional Especializado) na cidade de Euclides da Cunha, uma vez que segundo a entrevista, o mesmo possui

duas salas com funcionamento de $40 \mathrm{~h}$ semanais, sendo que cada criança fica $1 \mathrm{~h}$ por semana. Na escola Alice dos Anjos são atendidas crianças a partir dos 12 anos e na escola Erotildes Siqueira da Educação Infantil aos 10 anos. Há também 03 psicopedagogas que realizam o atendimento. Elas desenvolvem o trabalho de itinerância $01 x$ por semana, atendendo nas instituições.

É pertinente evidenciar que o ensino viabilizado no AEE deve ser dissemelhante do ensino escolar e não ser visualizado como um ambiente de reforço. Mas, com atividades práticas que o auxiliem no desenvolvimento de suas habilidades. Frente a isso, constata-se que já é um fator positivo esse funcionamento efetivo na cidade, visto que este é financiado pela municipalidade e está conforme a Constituição Federal de 1988, em seu Art. 208, Inciso III, que o "atendimento educacional especializado aos portadores de deficiência, deve se dar preferencialmente na rede regular de ensino" (Brasil, 1988, p. 70).

Vale argumentar ainda que outro elemento que impressiona é o quantitativo de docentes especializados e atuando na área apenas "05", dentre um grupo de aproximadamente 600 profissionais em educação. A Lei de Diretrizes e Bases da Educação Brasileira ํㅜ 9.394/96 vem confirmar que os sistemas de ensino devem assegurar principalmente professores especializados ou devidamente capacitados para atuar com qualquer pessoa especial na sala de aula. Então, emergem diversos questionamentos nas entrelinhas: Como disponibilizar meios mais acessíveis para os professores? Quais fatores impedem o educador de se especializar e se capacitar? Falta de recursos financeiros? Ausência da disponibilização de cursos? Desinteresse docente? Como assegurar e oferecer educação de qualidade sem a qualificação?

Durante a sondagem, foi possível verificar que as escolas recebem diversos tipos de deficiência, como: baixa-visão, intelectual, física, TDH, auditiva, autismo (a mais comum) e que para trabalhar com esses alunos, há o auxílio do cuidador para a criança que necessita exclusivamente do autocuidado. Diante desta situação, entende-se que, a educação euclidense dialoga e põe em prática um dos objetivos trazidos pela Constituição Federal de 1988, no cap. IV, que é de assegurar o acesso, a participação e a aprendizagem dos discentes com deficiência, bem como os transtornos globais do desenvolvimento e altas habilidades/superdotação nas escolas regulares, fazendo com que os sistemas de ensino promovam respostas às necessidades educacionais especiais, garantindo que não haja exclusão do sistema educacional. Contudo, pode-se inferir que focam bastante no autismo, visto que 
é uma das necessidades mais recorrentes, o que, possivelmente, pode resultar na "não-assistência" adequada para os educandos com outras necessidades.

A legislação vem dando suporte no que tange ao ingresso desses discentes, pois os mesmos têm a matrícula assegurada e necessitam ser incluídos adequadamente. Dentre as dificuldades identificadas, que provavelmente são comuns às diversas cidades, é relevante mencionar que o município já está regularizado conforme o ingresso e a garantia da matrícula dos discentes com necessidades especiais. Já que existem casos de escolas que se negam a cumprir as leis.

Outro fator que pode ser salientado é que existem poucos recursos pedagógicos e as formações não conseguem envolver todos os docentes da rede e que são os educadores que constroem seus próprios subsídios para ministrar suas aulas. Algo que fica nítido na fala da professora entrevistada, anteriormente citada nas páginas desse artigo, bem como na resposta da coordenadora quando é questionado sobre quais os recursos humanos, materiais e financeiros envolvidos nas ações voltadas para as propostas inclusivas e a mesma argumenta na entrevista do anexo $\mathrm{n}-2$, que

quando tem relatório, com base no senso, enviam algumas coisas: computadores e recursos para a sala multifuncional. Os professores também são agentes na confecção de materiais, pois produzem muito, como: alfabeto em braile e outros recursos. Em uma determinada escola, por exemplo, um aluno foi contemplado com um livro em braile (Entrevista, anexo ํㅜ 2, questão 9, 2019).

No que diz respeito ao fornecimento, pela Secretaria de Educação, de suportes pedagógicos ou cursos para capacitar os professores a fim de facilitar o trabalho em sala de aula, foi relatado na entrevista que está sendo realizado o Curso de Deficiência visual e cegueira e o Congresso Municipal de Inclusão que acontece desde 2017, envolvendo professores e coordenadores do município, só que apenas 03 profissionais podem participar. Além disso, há uma parceria com a coordenadora que ministra cursos nas instituições escolares, a participação nos eventos do SEEBA e a parceria com o Instituto de cegos em Salvador.

Diante do exposto, é cândido que, apesar dos obstáculos, a municipalidade está procurando, mesmo com "passos sutis", estabelecer parcerias, oferecer formação continuada e espaços para reflexão sobre a prática docente. Porém, isso ainda é pouco perante as dificuldades que os docentes encontram em sala de aula, até porque, nesses eventos e capacitação, nem todos têm a oportunidade de participar. Além disso, tentam assistir os educandos com necessidades especiais.

\section{O QUE BUSCAMOS, PLANTAMOS E COLHEMOS}

Conforme o PNE (Lei n 10.172/2001) "o grande avanço que a década da educação deveria produzir seria a construção de uma escola inclusiva que garanta o atendimento à diversidade humana" (BRASIL, 2001). Diante dessa afirmação, da entrevista com a docente e o levantamento de dados, pode-se inferir que a presente pesquisa, trouxe à tona o quanto ainda está distante a 
tão sonhada e batalhada Educação Inclusiva, visto que ficou perceptível que a maioria das leis e dos decretos está apenas no "papel".

No contexto atual, a cidade de Euclides da Cunha, caminha a "passos sutis" e que, aparentemente, boa parte dos discentes está apenas inserida, termo que difere de inclusão. Essa realidade precisa ser transformada, a educação inclusiva necessita de "um olhar minucioso", olhar com respeito e compromisso, já que são direitos garantidos pela legislação. De nada adianta o educando estar na escola e não se sentir pertencente a ela e nem no meio social. Por essa razão, o município necessita tomar atitude práticas, a citar: ter um mapa de dados para assim visualizar a "realidade" da educação inclusiva, focar nos problemas da implantação das leis, buscar parcerias e programas financiados pelo governo.

É sabido que, uma das diretorias da SECADI (Secretaria de Educação Continuada, Alfabetização, Diversidade e Inclusão) é a Diretoria de Políticas de Educação Especial (DPEE) que promove ações, estudos e programas, como: Programa Escola Acessível, Transporte Escolar Acessível, Formação Continuada de Professores na Educação Especial, BPC na Escola, Livro Acessível, Centro de Formação e Recursos (CAP, CAS e NAAHS), dentre outras. Apesar das dificuldades em aderir esses programas, o município poderia lutar para aderir bem como criar suas próprias políticas públicas voltadas para a realidade da cidade.

\section{PERCURSO METODOLÓGICO}

O presente trabalho teve como base a investigação bibliográfica de autores e obras que comunguem das ideias em estudo das quais, pode-se citar: a Constituição Federal Brasileira, Lei de Diretrizes e Base da Educação Nacional - LDB, documentos e decretos que tratam da educação especial e inclusiva, bem como da dos surdos. Para tanto, foi necessário a realização de uma pesquisa "in loco" com entrevista com uma docente municipal e levantamento de dados recolhidos na Secretaria da Educação da cidade de Euclides da Cunha. Depois, houve a análise para a comprovação da problemática em estudo - a falta da efetivação das leis que permitem a acessibilidade da pessoa com deficiência no espaço escolar.

\section{CONSIDERAÇÕES FINAIS}

No cenário atual, ao analisar a educação especial na perspectiva inclusiva, embasados nos documentos que tratam sobre as políticas públicas educacionais, nota-se que há decretos, leis e diretrizes que sustentam toda forma de inclusão seja ela sociocultural e econômica, na sala de aula e na sociedade. Contudo, esses termos estão distantes de chegarem ao ideal, visto que existem diversos empecilhos para a efetivação da legislação e no que tange à educação dos surdos, esta, exclusivamente no município, quase não existe, visto que focam apenas nas deficiências mais recorrentes, no caso, o autismo.

Diante do estudo desenvolvido sobre esta temática, percebeu-se que há uma dissonância significativa ente as leis e a realidade. Apesar de toda consciência de que a educação é um direito de todos os indivíduos, ainda 
existem obstáculos a serem superados e novos desafios a serem traçados. Os "passos são sutis", mas já se mostram relevantes. Conquanto, há de se ir sempre mais além para poder se aproximar do ideal dentro das políticas e ações inclusivas. Os meios legais citados durante a pesquisa viabilizam estabelecer novas políticas e devem ser convertidos num compromisso de todos.

Com esse objeto de pesquisa, foi despertado um novo olhar sobre a educação inclusiva e a legislação que a asseguram, induzindo a um grande desafio que é de oferecer aos educandos com necessidades específicas, uma educação de qualidade, com escolas bem planejadas e preparadas para atender e possibilitar o desenvolvimento das competências e habilidades, levando em consideração não somente as necessidades como também suas potencialidades. O que fica perceptível é que, por exemplo, os docentes aceitam a Educação Inclusiva, mas devido às dificuldades, já mencionadas durante esse artigo, não acreditam que existam condições para que ela exista. Assim, o aluno passa a ser excluído novamente, mesmo com o ingresso na instituição escolar.

Há muito que se fazer: acessibilidade, recursos adequados, cursos de especialização e formação dos docentes, parcerias com a família e comunidade, criação de espaços para discussões sobre a inclusão, o funcionamento adequado do AEE. Sem esquecer-se de mencionar, o papel dos três governos: Federal, Estadual e Municipal a fim facilitar a efetivação das leis, uma vez que é sabido que existem diversas restrições, burocracias que dificultam a aquisição dos programas e ações governamentais.

Por fim, é essencial aditar que a luta por uma educação inclusiva deve estar pautada nas políticas públicas, mesmo havendo ainda instituições com sistemas excludentes, a fim de contribuir para a mobilização da sociedade e fazer com que haja a implantação adequada do sistema de ensino inclusivo, já que todas as pessoas, independente de suas limitações, têm o direito de se sentir cidadão, pertencente a uma comunidade e de ampliar as suas competências, habilidades para se obter qualidade de vida.

\section{REFERÊNCIAS}

AMARO, Daniel. Edição do Brasil. Disponível em: http:///editoradobrasil.com.br. Quase 10 milhões de brasileiros possuem deficiência auditiva Acesso em: 20 de abril de 2019.

BRASIL. Constituição da República Federativa do Brasil. Brasília: Imprensa Oficial, 1988.

BRASIL. Constituição da República Federativa do Brasil. Brasília: Imprensa Oficial, 1988.

BRASIL. Ministério da Educação. Lei de Diretrizes e Bases da Educação Nacional, LDB 9.394. Brasília, 1996.

BRASIL. Ministério da Educação. Lei no 10.172. Aprova o Plano Nacional de Educação e dá outras providências. Brasília: MEC, 2001. 
BRASIL. Ministério da Educação. Secretaria da Educação Especial. Política Nacional de Educação Especial. Brasília: MEC/SEESP, 1994.

BRASIL. Ministério da Educação. Secretaria de Educação Especial. Lei oㅡ 10.436, de 24 de abril de 2002. Dispõe sobre a Língua Brasileira de Sinais LIBRAS e dá outras providências.

BRASIL. Ministério da Educação. Secretaria de Educação Especial. Política Nacional de Educação Especial. Brasília: MEC/SEESP, 2008.

GESSER, Audrei. O Ouvinte e a surdez. São Paulo: Parábola Editorial, 2012.

MACEDO, Yuri Miguel; OLIVEIRA, Eduardo David; PEÇANHA, Cinézio Feliciano. A CAPOEIRA COMO REFERENCIAL METODOLÓGICO PARA ENFRENTAMENTO DO RACISMO. Revista da Associação Brasileira de Pesquisadores/as Negros/as (ABPN), [S.I.], v. 11, n. Ed. Especi, p. 174-187, out. 2019. ISSN 2177-2770.

MAZZOTA, Marcos J.S. Educação Especial no Brasil: História e políticas públicas. São Paulo: Cortez Editor, 2001. 